CADEMARTORI, Daniela Mesquita Leutchuk; MORAES, Gabriel Augusto Marques Poeta de. A construção da cidadania, a democracia e a teoria cosmopolita: análise de um caso a partir do fenômeno das iterações democráticas. Revista Eletrônica Direito e Política, Programa de PósGraduação Stricto Sensu em Ciência Jurídica da UNIVALI, Itajaí, v.10, n.2, 10 quadrimestre de 2015. Disponível em: www.univali.br/direitoepolitica - ISSN 1980-7791.

\title{
A CONSTRUÇÃO DA CIDADANIA, A DEMOCRACIA E A TEORIA COSMOPOLITA: ANÁLISE DE UM CASO A PARTIR DO FENÔMENO DAS ITERAÇÕES DEMOCRÁTICAS
}

\author{
CONSTRUCTION OF CITIZENSHIP, DEMOCRACY AND THE COSMOPOLITAN \\ THEORY: ANALYSIS OF A CASE FROM THE DEMOCRATIC ITERATIONS \\ PHENOMENON
}

\section{Daniela Mesquita Leutchuk de Cademartori ${ }^{1}$}

Gabriel Augusto Marques Poeta de Moraes²

SUMÁRIO: Introdução; 1. A Teoria Cosmopolita: de Kant a Benhabib; 2. O desenvolvimento da cidadania clássica e o fenômeno das "iterações democráticas"; Conclusões Provisórias; Referências das fontes citadas; Anexos.

RESUMO: Esse ensaio objetiva perceber questões estruturais da Teoria Cosmopolita, inicialmente desenvolvida por Immanuel Kant em "A Paz Perpétua" e contemporaneamente revisada pela autora turca Seyla Benhabib na obra Another Cosmopolitanism $O$ ponto nevrálgico a ser analisado aqui será a aplicação do processo de Iterações Democráticas na observação de um caso específico ( $L$ 'Affaire du Foulard) e como esse fenômeno, percebido num contexto de antecipação de novas modalidades de cidadania, pode ajudar a entender e contribuir para a democracia e o desenvolvimento de uma ideia mais adequada de sociedade civil global.

Palavras-Chave: Teoria Cosmopolita; Iterações Democráticas; Cidadania; L'Affaire du Foulard.

ABSTRACT: This essay looks for analyze structural issues about the Cosmopolitan Theory, encouraged by Immanuel Kant in "Perpetual Peace" and contemporaneously analyzed by the turkish author Seyla Benhabib in "Another Cosmopolitanism". The critical point to be considered here is the application process in the "Democratic Iterations" analysis of a specific case (The Scarff Affair) and how this phenomenon, seen in the context of anticipating new forms

\footnotetext{
${ }^{1}$ Doutora e Mestre em Direito pela UFSC. Professora da Graduação e do Programa de PósGraduação em Direito da Unilasalle (Canoas -RS). E-mail: daniela.cademartori@unilasalle.edu.br

${ }^{2}$ Acadêmico do Curso de Relações Internacionais da Unilasalle (Canoas - RS). Bolsista de Iniciação Científica. EMAIL: gugapoeta@gmail.com
} 
CADEMARTORI, Daniela Mesquita Leutchuk; MORAES, Gabriel Augusto Marques Poeta de. A construção da cidadania, a democracia e a teoria cosmopolita: análise de um caso a partir do fenômeno das iterações democráticas. Revista Eletrônica Direito e Política, Programa de PósGraduação Stricto Sensu em Ciência Jurídica da UNIVALI, Itajaí, v.10, n.2, $1^{0}$ quadrimestre de 2015. Disponível em: www.univali.br/direitoepolitica - ISSN 1980-7791.

of citizenship can help to understand and contribute to develop a better overall view of civil society.

Keywords: Cosmopolitan Theory; Democratic Iteration; Citizenship; The Scarff Affair.

\section{INTRODUÇÃO}

Como o conceito de cidadania não possui um significado estanque, variando no tempo e no espaço, na perspectiva da titularidade e do conteúdo, a análise de seu processo de ampliação deixa evidente o caráter de construção e de luta por direitos, caráter esse que se configura em seu conceito contemporâneo. $\mathrm{Na}$ atualidade, se por um lado, ela é um conjunto de direitos civis, políticos e sociais, por outro, um sentimento comunitário de participação e, portanto, significa a exclusão dos integrantes que não comungam desses sentimentos. Por outro lado, só recentemente, na linguagem dos juristas a cidadania deixou de significar apenas o sentido de nacionalidade e foi ampliada no sentido de um status de cidadão envolvendo direitos. Como a auto-compreensão do Estado Democrático de Direito envolve o princípio da voluntariedade, as características convencionais do jus soli e do jus sanguinis são insuficientes para fundamentar uma submissão irrevogável ao poder soberano do Estado.

Com o desenrolar do recente processo de globalização ${ }^{3}$, presencia-se uma nova realidade no que diz respeito aos movimentos migratórios. Com o passar dos anos, esses movimentos vêm se intensificando ${ }^{4}$ pelos mais diversos motivos sociais, culturais, econômicos, políticos, motivados por guerras e até mesmo por desastres naturais. Ressalte-se que, na sua maioria, as migrações não tem um

\footnotetext{
3 "Aumento da interdependência entre diferentes povos, regiões e países do mundo à medida que as relações sociais e econômicas passam a abranger o mundo inteiro." (GIDDENS, Anthony. Sociologia. Tradução de Sandra Regina Netz. 4.ed. Porto Alegre: 2005, p. 568)

${ }^{4}$ Conforme relatório da Organização das Nações Unidas, lançado em setembro de 2015, existem 232 milhões de migrantes internacionais. O relatório afirma ainda que de 2010 a 2013 o destino com maior fluxo de migrantes foi de fato a Europa, com cerca de 1,1 milhão de migrantes por ano. (CF. UNITED NATIONS. General Assembly. International Migration and Development - Report of the Secretary-General. Disponível em: http://www.un.org/esa/population/migration/ga/SG_Report_A_68_190.pdf. Acesso em: 21 de março de 2014)
} 
CADEMARTORI, Daniela Mesquita Leutchuk; MORAES, Gabriel Augusto Marques Poeta de. A construção da cidadania, a democracia e a teoria cosmopolita: análise de um caso a partir do fenômeno das iterações democráticas. Revista Eletrônica Direito e Política, Programa de PósGraduação Stricto Sensu em Ciência Jurídica da UNIVALI, Itajaí, v.10, n.2, $1^{\circ}$ quadrimestre de 2015. Disponível em: www.univali.br/direitoepolitica - ISSN 1980-7791.

caráter temporário. Pelo contrário, as pessoas acabam fixando-se no local de destino, construindo verdadeiros laços sociais, políticos e até mesmo culturais: arranjam emprego, participam da economia, mesmo que informalmente e o mais relevante, constroem famílias.

O fato é que, a priori, dependendo do lugar em que "estrangeiro" se fixar, ele pode não ter os direitos sociais e políticos de que gozava em outro local. Além disso, existem as diferenças culturais que muitas vezes são conclamadas para justificar a exclusão e não aceitação de um estrangeiro no ambiente socialpolítico do novo território.

Para embasar a participação de estrangeiros na vida social e política em outro local que não o seu de origem, considerar-se-á as contribuições da Teoria Universalista ou Cosmopolita, desenvolvida a partir de Immanuel Kant em "A Paz Perpétua". Os aportes dessa teoria possibilitam começar a pensar a concepção do individuo em uma, mesmo que por enquanto utópica, sociedade civil global. Vivenciando sua lógica é possível também identificar as fendas éticas existentes no modelo democrático liberal, responsável, por exemplo, pelo julgamento dos valores que permeiam a inserção política do indivíduo estrangeiro na sociedade. Esses valores, fundamentam as leis de não-inserção do estrangeiro na vida política do país e a sua formulação se dá sem a devida participação daqueles que são objeto da proteção. Na sequência, tratar-se-á do fenômeno descrito por Seyla Benhabib como "Iterações Democráticas" - num contexto de busca de novas modalidades de cidadania - capaz de representar uma mediação na formação da vontade e da opinião pública, a partir da análise caso conhecido como L'Affaire du Foulard. Pretende-se demonstrar como esse processo pode auxiliar à compreensão e ao desenvolvimento da noção de sociedade civil global.

\section{A TEORIA UNIVERSAL (COSMOPOLITA): DE KANT A BENHABIB}

Ao contrário do que parece à primeira vista, o sentido conotativo da Teoria Cosmopolita em nada se assemelha ao direito internacional. Em síntese, o direito internacional, difundido e apoiado principalmente na figura do Estado, opõe-se à 
CADEMARTORI, Daniela Mesquita Leutchuk; MORAES, Gabriel Augusto Marques Poeta de. A construção da cidadania, a democracia e a teoria cosmopolita: análise de um caso a partir do fenômeno das iterações democráticas. Revista Eletrônica Direito e Política, Programa de PósGraduação Stricto Sensu em Ciência Jurídica da UNIVALI, Itajaí, v.10, n.2, 10 quadrimestre de 2015. Disponível em: www.univali.br/direitoepolitica - ISSN 1980-7791.

ideia do Cosmopolitismo que busca aproximar-se às necessidades do individuo em um contexto globalizado. Para ilustrar a necessária transição do direito internacional para um ideal Cosmopolita, a filósofa turca Seyla Benhabib menciona dois conceitos que, erroneamente, têm sido usados para descrever tal transição: império e globalização. ${ }^{5}$

No caso do conceito de império, há ainda a distinção entre império e imperialismo. Ao passo que imperialismo denota a ideia de um movimento predatório, extrativo, e de ordem exploratória, na qual cada soberania impõe seus anseios às outras, a noção de império refere-se a uma rede anônima de regras, regulações e estruturas que "dragam" o individuo para o sistema global de capitalismo. ${ }^{6}$ A ideia de império envolve uma hegemonia sem um centro. Neste fluxo, percebe-se na globalização, uma descontinuidade na propagação dos mercados livres e das práticas comerciais e a dos direitos humanos.

Este é o "impulso" a que se refere Benhabib no inicio da obra "Another Cosmopolitanism". Se o resultado da globalização é pobre e a versão canalizada pelos teóricos do império é vazia no que tange a mensurar o desenvolvimento do fenômeno Cosmopolita, este não deve ser o cerne da discussão. O que deve ser considerado é que, embora a evolução das normas cosmopolitas seja gradativa, sua relação com as instituições democráticas é ainda frágil, tanto

\footnotetext{
${ }^{5}$ Seyla Benhabib menciona dois conceitos que, erroneamente, tem sido usados para descrever tal transição: império e globalização. (BENHABIB, Seyla. Another Cosmopolitanism. Oxford: Oxford University Press, 2006, p. 16)

${ }^{6}$ De acordo com Antonio Negri e Michael Hardt, o imperialismo pode ter acabado, mas o Imperio uma nova ordem política, surgida no contexto da globalização - está em expansão. Com o declínio da soberania dos Estados-nação - "pedra angular" do imperialismo que as potências europeias construíram na idade moderna -, a soberania tomou uma nova forma, "composta de uma série de organismos nacionais e supranacionais, unidos por uma lógica ou regra única": o império. "Entendemos 'Império', entretanto, como algo completamente diverso de 'imperialismo'. As fronteiras definidas pelo moderno sistema de Estados-nação foram fundamentais para o colonialismo europeu e para a expansão econômica: os limites territoriais do país delimitavam o centro de poder a partir do qual era exercido o controle sobre territorios externos por meio de um sistema de canais e barreiras que, sucessivamente, facilitavam e obstruíam o fluxo de produção e circulação. O imperialismo era, na realidade, uma extensão da soberania dos Estados-nação europeus além de suas fronteiras. Finalmente, quase todos os territorios existentes puderam ser parcelados e o mapa mundial pôde ser codificado em cores europeias: vermelho para os territorios britânicos, azul para franceses, verde para portugueses. Onde quer que deitassem raízes, a soberania moderna construía um Leviatã que cobria como um arco seu dominio social e impunha fronteiras territoriais hierárquicas, para fiscalizar a pureza de sua identidade e para excluir tudo que representasse o outro." (HARDT, Michael; NEGRI, Antonio. Império. Tradução de Berilo Vargas. 6.ed. Rio de Janeiro: Record, 2004, p. 12 e 13)
} 
CADEMARTORI, Daniela Mesquita Leutchuk; MORAES, Gabriel Augusto Marques Poeta de. A construção da cidadania, a democracia e a teoria cosmopolita: análise de um caso a partir do fenômeno das iterações democráticas. Revista Eletrônica Direito e Política, Programa de PósGraduação Stricto Sensu em Ciência Jurídica da UNIVALI, Itajaí, v.10, n.2, $1^{\circ}$ quadrimestre de 2015. Disponível em: www.univali.br/direitoepolitica - ISSN 1980-7791.

teórica como politicamente. Ou seja, o estudo desse fenômeno terá de girar em torno da seguinte questão: como o desejo democrático - suas instituições - deve relacionar-se com as normas cosmopolitas de justiça? Como normas advindas "de fora" das legislações democráticas, poderão ser compatíveis com a democracia? ${ }^{7}$

Três tipos de pensamento alinham-se com o conceito de cosmopolitismo. O primeiro tipo considera que ele é uma atitude geral que não se encaixa nos conceitos de amor à pátria e "amor à humanidade", sendo a pensadora Martha Nussbaum uma de suas defensoras. Para outros, tais como Jeremy Waldrom, cosmopolitismo significa hibridismo, fluidez e reconhecimento das fragilidades do ser humano e das civilizações: a complexidade das sociedades não pode ser "encoberta" por fantasias nacionalistas de comunidades "primitivas". E por fim, existem aqueles que embasam suas convicções em uma crítica de caráter mais teórico e consideram o caráter filosófico e normativo do conceito. Para eles, o cosmopolitismo carrega consigo normas universais de discursos éticos que estão acima dos confins do Estado-nação. ${ }^{8}$

Ainda que Benhabib tenha simpatias pelo último discurso, ela também lhes tece críticas. Por exemplo, dentro da temática que ela denomina de "escopo do discurso", a questão do paradoxo do pertencimento à comunidades delimitadas. Aqui fica claro o fato que a "conversação moral" não pode limitar-se aos que se encontram no interior das "comunidades delimitadas". Partindo de uma discussão universalista/cosmopolita, entende-se que inclusive os estados fronteiriços requerem uma "moral justificadora". Ou seja, a "conversação moral" ou a "obrigação" que um cidadão tem para com o próximo de justificar suas ações, transcende as amarras geográficas dos entes estatais, uma vez que as consequências dos deveres e obrigações morais não se limita às características geográficas. O que ocorre hoje é que as normas que regulam as "novas adesões" impactam principalmente os que não são, a priori, membros. Eles são diferenciados entre "os de dentro, pelos de fora", "os cidadãos, dos não

\footnotetext{
7 BENHABIB, Seyla. Another Cosmopolitanism...p. 17

8 BENHABIB, Seyla. Another Cosmopolitanism...p. 17-20
} 
CADEMARTORI, Daniela Mesquita Leutchuk; MORAES, Gabriel Augusto Marques Poeta de. A construção da cidadania, a democracia e a teoria cosmopolita: análise de um caso a partir do fenômeno das iterações democráticas. Revista Eletrônica Direito e Política, Programa de PósGraduação Stricto Sensu em Ciência Jurídica da UNIVALI, Itajaí, v.10, n.2, $1^{0}$ quadrimestre de 2015. Disponível em: www.univali.br/direitoepolitica - ISSN 1980-7791.

cidadãos", salientando-se que estas normas não são nem mesmo desenvolvidas pelos que são considerados sujeitos "protegidos" pelas mesmas, ou seja, os cidadãos de fato. Aqui Benhabib estende sua crítica à democracia, uma vez que a moral do discurso democrático não necessariamente se baseia em prerrogativas éticas.

Para que o discurso universalista se desenvolva, não pode ocorrer uma redução das conceptualizações. Por exemplo, diferente dos comunitaristas que reduzem as demandas da moralidade aos desejos validados por uma cultura e/ou comunidade política portadora de uma ética específica e ainda, dos realistas e pós-modernistas - céticos ao afirmar que as normas políticas podem sempre ser julgadas à luz da moral - deve prevalecer a distinção, bem como a mediação, da moral e da ética e da moral e da política. Pergunta-se então, como alguém pode mediar um universalismo moral com preceitos éticos particulares? Como alguém conseguirá mediar normas políticas legais com uma moral restritiva? A mediação aqui não é uma mera redução e sim, é de muito mais valia. Para a resolução deste contencioso defende-se a ideia do Cosmopolitismo, que na concepção da autora é um projeto filosófico de mediações ou de intervenções, não de reduções ou totalizações. A Teoria Cosmopolita não é equivalente a uma ética global, nem caracteriza-se por atitudes culturais e escolhas pontuais. Este ideal, na sua justificação, segue a lógica kantiana:

[...] pensando o cosmopolitismo como normas emergentes que buscam governar as relações entre os indivíduos em uma sociedade civil global. Estas normas não são nem somente morais nem somente legais. Elas são melhor caracterizadas como uma concepção da moralidade da lei, mais em uma ordem global do que local. ${ }^{9}$

Kant não aceita a utilização do positivismo jurídico, bem como a do direito natural. Sobre o positivismo jurídico, Benhabib explica que qualquer ceticismo ou qualquer outro critério invocado contra o sistema, acaba por debater ou avaliar. Desagua-se em normas que transcendem à lógica da legalidade e à crítica moral.

\footnotetext{
9 " $[\ldots]$ thinking of cosmopolitanism as the emergence of norms that ought to govern relations among individuals in a global civil society. These norms are neither merely moral nor just legal. They may best be characterized as framing the morality of the law, but in a global rather than a domestic order." (tradução livre - BENHABIB, Seyla. Another Cosmopolitanism... p. 20)
} 
CADEMARTORI, Daniela Mesquita Leutchuk; MORAES, Gabriel Augusto Marques Poeta de. A construção da cidadania, a democracia e a teoria cosmopolita: análise de um caso a partir do fenômeno das iterações democráticas. Revista Eletrônica Direito e Política, Programa de PósGraduação Stricto Sensu em Ciência Jurídica da UNIVALI, Itajaí, v.10, n.2, $1^{\circ}$ quadrimestre de 2015. Disponível em: www.univali.br/direitoepolitica - ISSN 1980-7791.

A legalidade representa por si só uma situação fora dela mesma, um "extralegal". Já sobre o direito natural, a autora considera que fixar uma natureza humana é por demasia um trabalho de aprofundamento metafísico do ser humano, o que faz com que ele seja percebido como uma entidade e não como o ser que é. Prefere os termos "existência humana" ou "condições humanas", pois eles, diferentemente dos conceitos do direito natural, referem-se àquelas circunstancias intrínsecas vinculadas à vida que é "dada" ao ser humano. Tais circunstâncias limitam suas escolhas, apesar dele continuar livre para escolher os caminhos do futuro. Demonstrando esses pontos, a questão levantada pela doutrina kantiana é a seguinte: ainda que o direito natural não possa ser defendido e o positivismo jurídico seja moralmente suspeito, como pode-se subsidiar teoricamente a condenação dos crimes contra a humanidade?

Percebe-se aqui a inovação introduzida pela teoria kantiana no que concerne ao significado do direito, ao reconhecer o inter-relacionamento de seus três diferentes níveis. O primeiro, envolve as leis domésticas; o segundo, a esfera jurídica das relações entre os Estados, e por fim, o Direito Cosmopolita, referente às relações entre civis, bem como entre entidades políticas numa sociedade civil global. Na obra A Paz Perpétua, Kant introduz o termo "Direito Cosmopolita" ao referir-se ao dever de hospitalidade, considerando-o como um direito e não como uma mera filantropia. A questão aqui é de se o direito à hospitalidade, entendido como parte das relações entre os indivíduos e os Estados, envolve atos de obrigação (com justificativa moral no ato de altruísmo) ou se conclama a moral que envolve os direitos da humanidade. Identifica-se um dilema que afeta também as discussões de asilo e refúgio. ${ }^{10}$

Seguindo ainda a obra de Kant como norteadora de seu estudo, Benhabib menciona "o espaço" existente entre as "normas positivas" e as normas universais. Kant presume a mudança da "soberania westphaliana" para a "soberania internacional liberal" como predecessora do fenômeno cosmopolita. $\mathrm{Na}$ transição estava pressuposto um novo conceito de soberania que não mais

10 Cf. KANT, Immanuel. A Paz Perpétua: um projeto filosófico. Tradução de Artur Mourão. Covilhã: Universidade da Beira Interior, 2008. Disponível em: www.lusofonia.net. Acesso em: 22 de março de 2014 
CADEMARTORI, Daniela Mesquita Leutchuk; MORAES, Gabriel Augusto Marques Poeta de. A construção da cidadania, a democracia e a teoria cosmopolita: análise de um caso a partir do fenômeno das iterações democráticas. Revista Eletrônica Direito e Política, Programa de PósGraduação Stricto Sensu em Ciência Jurídica da UNIVALI, Itajaí, v.10, n.2, 10 quadrimestre de 2015. Disponível em: www.univali.br/direitoepolitica - ISSN 1980-7791.

significava ultimatos e autoridade arbitrária por sobre um território. Atualmente, Estados que violam os direitos dos seus cidadãos, fecham suas fronteiras, engessam o livre comércio e sufocam a liberdade de expressão, podem até ser "excluídos" de algumas sociedades de Estados (União Europeia e Mercosul, por exemplo) ou alianças. Embora Kant considere que os Estados sejam historicamente os principais sujeitos do direito internacional e das entidades políticas organizadas, aduz que as normas cosmopolitas vão além da soberania liberal internacional, pois ensejam um espaço jurídico e conceitual de relações de direitos trazidos à tona por atores estatais e não-estatais, quando estes entram em contato com indivíduos que não fazem parte de suas políticas. ${ }^{11}$

\section{O DESENVOLVIMENTO DA CIDADANIA CLÁSSICA E O FENOMENO DAS "ITERAÇÕES DEMOCRÁTICAS"}

\subsection{A conceito clássico de cidadania}

A cidadania encontra na obra de Thomas H. Marshall ${ }^{12}$ uma de suas grandes análises: a que reabre o tema para um amplo debate de revisão e crítica à noção liberal do conceito. Menos com base na lógica do que na história, Marshall divide o conceito de cidadania em três noções: a civil, a política e a social, vinculando-a a correlatos direitos.

Os direitos civis são os necessários à liberdade individual, salientando-se aqui as liberdades de ir e vir, de imprensa, de pensamento, de fé, à propriedade, de concluir contratos válidos e à justiça. De seu lado, os direitos políticos compreendem o direito do cidadão de "participar no exercício do poder político", seja como eleitor ou como integrante de organismo político investido de autoridade. Eles correspondem às instituições parlamentares e aos conselhos dos Governos locais. Já os direitos sociais abrangem desde o direito a desfrutar de

\footnotetext{
${ }^{11}$ BENHABIB, Seyla. Another Cosmopolitanism... p. 20

12 Cf. MARSHALL, Thomas Humphrey. Cidadania, classe social e status. Tradução de Meton Porto Gadelha. Rio de Janeiro: Zahar, 1967. 220p. Título original: Sociology at the Crossroads and other essays
} 
CADEMARTORI, Daniela Mesquita Leutchuk; MORAES, Gabriel Augusto Marques Poeta de. A construção da cidadania, a democracia e a teoria cosmopolita: análise de um caso a partir do fenômeno das iterações democráticas. Revista Eletrônica Direito e Política, Programa de PósGraduação Stricto Sensu em Ciência Jurídica da UNIVALI, Itajaí, v.10, n.2, 10 quadrimestre de 2015. Disponível em: www.univali.br/direitoepolitica - ISSN 1980-7791.

uma situação mínima de bem-estar e segurança até o direito "de participar, por completo, na herança social e levar a vida de um ser civilizado de acordo com os padrões que prevalecem na sociedade. As instituições mais ìntimamente ligadas com ele[s] são o sistema educacional e os serviços sociais."13

Deste modo, parte-se de uma definição inicial de cidadania que tem como pressuposto o reconhecimento por parte do Estado aos indivíduos que o integram de uma série de direitos. São direitos iniciais da cidadania no Estado Liberal os direitos civis e os políticos, estes últimos envolvendo a participação dos indivíduos nos destinos da sociedade, votando e sendo votados. Ter direito a participar dos destinos da sociedade significa ter direito à democracia ${ }^{14}$. No entanto, direitos civis e políticos não garantem a democracia sem os direitos sociais, capazes de possibilitar a participação do indivíduo na riqueza coletiva: o direito à educação, ao trabalho, a um salário justo, à saúde, a uma velhice tranquila. ${ }^{15}$

\footnotetext{
${ }^{13}$ MARSHALL, Thomas Humphrey. Cidadania, classe social e status... p.63-4

${ }^{14}$ Para Norberto Bobbio, a única maneira de se compreender a democracia enquanto contraposta a outras formas autoritárias de governo, é aquela que a considera como "um conjunto de regras (primárias ou fundamentais) que estabelecem 'quem' está autorizado a tomar as decisões coletivas e com quais 'procedimentos'." Para que a decisão seja considerada decisão coletiva é preciso que seja tomada com base em regras que estabelecem quais os indivíduos autorizados a tomar as decisões que irão vincular todos os membros do grupo e quais os procedimentos. Bobbio acrescenta três condições para a existência da democracia. A primeira diz respeito aos sujeitos que irão tomar as decisões coletivas: "um regime democrático caracteriza-se por atribuir este poder (que estando autorizado pela lei fundamental torna-se um direito) a um número muito elevado de integrantes do grupo." É preciso um juízo comparativo com base nas circunstâncias históricas para saber o número necessário daqueles que têm direito ao voto, a fim de considerar um regime democrático ou não. A segunda condição relaciona-se às modalidades de decisão. Neste caso a regra fundamental é a da maioria. Finalmente, pela terceira condição as alternativas postas aos chamados a decidir deverão ser reais e os mesmos devem ser colocados em posição de escolher entre uma ou outra. Como corolário, tem-se que o Estado liberal é um pressuposto histórico e jurídico do Estado democrático, já que deverão ser garantidos aos chamados a decidir os direitos de liberdade (de opinião, de expressão das próprias opiniões, de reunião, etc.). (BOBBIO, Norberto. O Futuro da democracia: uma defesa das regras do jogo Tradução de M. A. Nogueira. São Paulo: Paz e Terra, 1986. Título original: Il futuro della democrazia. Una difesa delle regole del gioco, p. 18,19 e 20)

${ }^{15}$ Reflexamente pode-se afirmar, junto com Norberto Bobbio, que é a própria democracia que leva aos direitos sociais ao mesmo tempo em que determina a passagem do Estado Liberal ao Estado Social: "A partir do momento em que o voto foi estendido aos analfabetos tornou-se inevitável que estes pedissem ao estado a instituição de escolas gratuitas; com isto, o estado teve que arcar com um ônus desconhecido pelo estado das oligarquias tradicionais e da primeira oligarquia burguesa. Quando o direito de voto foi estendido também aos não-proprietários, aos que nada tinham, aos que tinham como propriedade tão-somente a força de trabalho, a conseqüência foi que se começou a exigir do estado a proteção contra o desemprego e, pouco a pouco, seguros sociais contra as doenças e a velhice, providências em favor da maternidade, casas a preços populares, etc. Assim
} 
CADEMARTORI, Daniela Mesquita Leutchuk; MORAES, Gabriel Augusto Marques Poeta de. A construção da cidadania, a democracia e a teoria cosmopolita: análise de um caso a partir do fenômeno das iterações democráticas. Revista Eletrônica Direito e Política, Programa de PósGraduação Stricto Sensu em Ciência Jurídica da UNIVALI, Itajaí, v.10, n.2, 10 quadrimestre de 2015. Disponível em: www.univali.br/direitoepolitica - ISSN 1980-7791.

Por outro lado, o reconhecimento - por parte de um Estado determinado - dessa capacidade política e jurídica é o elemento que constitui os indivíduos em cidadãos. É de advertir-se que mesmo em regimes democráticos, diferentes disposições legais podem favorecer ou restringir, de modo mais ou menos aberto e sutil, o exercício efetivo destes direitos. O fato de que a cidadania pressupõe o reconhecimento de direitos por parte de um Estado suscita a questão do nacionalismo. Este, diz José Rubio Carracedo, coloca um sério problema tanto à cidadania quanto aos direitos humanos:

E é assim porque o nacionalismo segue uma lógica diferente, senão contraposta [...] Trata-se de uma lógica tendencialmente incluinte que, por isso mesmo, resulta ser excesivamente excluinte (pureza étnica, direitos históricos, língua própria, etc.). Não obstante, cabe uma concepção moderada de nacionalismo que não só é legítima, também é compatível - e até exigível - com o conceito complexo de cidadania e dos direitos humanos, ainda que implique um esforço ímprobo de equilibrio e de coragem. ${ }^{16}$

Concomitantemente à obra de Marshall, teóricos que impulsionaram o Estado Social de Direito ${ }^{17}$ contribuíram para a proposição de uma nova dimensão da cidadania que amplia seu conteúdo, integrando a este conceito uma série de direitos de índole econômica, social e cultural implícita no trânsito do Estado Liberal a um novo modelo social de Estado de Direito ${ }^{18}$. Com o Estado Social de

aconteceu que o estado de serviços, o estado social foi, agrade ou não, a resposta a uma demanda vinda de baixo, a uma demanda democrática no sentido pleno da palavra." (BOBBIO, Norberto. 0 Futuro da democracia... p. 34-5)

16 "Y ello es así porque el nacionalismo sigue una lógica distinta, si no ya contrapuesta [...] Se trata de una lógica tendencialmente incluyente que, por lo mismo, resulta excesivamente excluyente (pureza étnica, derechos históricos, lengua propia, etc.). No obstante, cabe una concepción moderada del nacionalismo que no sólo es legítima, sino también compatible - y hasta exigible con el concepto complejo de ciudadanía y de los derechos humanos, aunque implique un esfuerzo ímprobo de equilibrio y de coraje." (tradução livre - RUBIO CARRACEDO, José. Introducción. In: ; ROSALES, José Maria; TOSCANO MÉNDEZ, Manuel. Ciudadanía, nacionalismo y derechos humanos. Madrid: Trotta, 2000, p. 11)

17 "O Estado Social de Direito, também denominado de Estado do Bem-Estar, distingue-se justamente por ter avocado para si a tarefa de realização da justiça social, de tal sorte que, juntamente com os direitos sociais, pode ser considerado ao mesmo tempo produto, complemento, corretivo e limite do Estado Liberal de Direito e dos clássicos direitos de defesa de matriz liberalburguesa." (SARLET, Ingo Wolfgang. A eficácia dos direitos fundamentais. 3.ed. rev., atual. e amp. Porto Alegre: Livraria do Advogado, 2003, p. 233)

18 Tais proposições aparecem por exemplo na obra de Hermann Heller que dirá que frente às ditaduras totalitárias e a nomocracia em que desemboca a concepção formalista de Kelsen, o Estado Social de Direito deve supor, como resposta às demandas da democracia social do 
CADEMARTORI, Daniela Mesquita Leutchuk; MORAES, Gabriel Augusto Marques Poeta de. A construção da cidadania, a democracia e a teoria cosmopolita: análise de um caso a partir do fenômeno das iterações democráticas. Revista Eletrônica Direito e Política, Programa de PósGraduação Stricto Sensu em Ciência Jurídica da UNIVALI, Itajaí, v.10, n.2, 10 quadrimestre de 2015. Disponível em: www.univali.br/direitoepolitica - ISSN 1980-7791.

Direito, o discurso sobre a cidadania registra uma nova mudança de rumo. Para além do projeto da Ilustração que se contentava com assegurar a igualdade formal dos cidadãos, o Estado Social de Direito objetivou a promoção da igualdade real.

Hoje, a quebra de algumas das conquistas desse Estado - tais como o pleno emprego, educação, saúde e serviços assistenciais - possibilita a valoração de sua autêntica dimensão e do avanço emancipatório que, apesar de suas insuficiências, ele supôs nas sociedades de bem-estar. Para Pérez Luño, isto mostra a unilateralidade das críticas radicais da esquerda que desqualificavam o Estado Social, considerando-o como um mero gestor dos interesses capitalistas, um mecanismo para domesticar o movimento operário. ${ }^{19}$

\subsection{As iterações democráticas}

O conceito clássico de cidadania - cujo portador deve residir em um único território com representação administrativa burocrática e identidade coletiva, privilégios políticos de membro e direitos e deveres sociais - vem sofrendo "um leve" desenvolvimento. Cada vez mais, pessoas em todos os cantos do planeta veem-se em uma situação em que não estão participando de uma identidade coletiva, porém ainda assim gozam de certos direitos enquanto "trabalhadores estrangeiros" ou residentes permanentes. ${ }^{20}$

proletariado "la extensión del pensamiento del Estado de derecho material al orden del trabajo y de los bienes". (Heller, 1978, I, p. 165 apud PÉREZ LUÑO, A.E. Ciudadanía y definiciones. Doxa. Cuadernos de Filosofia del Derecho, Alicante, n. 25, p. 177-210, 2002. Disponível em: Acesso em: 22 de março de 2014, p. 189). Na Itália, o pensador e político socialista, Lélio Basso "[...] reivindicó el nuevo concepto de ciudadanía que dimana del Estado social de derecho. En su libro Il principe sensa cetro (Basso, 1958), sostiene el compromiso democrático y emancipatorio del Estado social y llega a afirmar que en dicha forma política cada ciudadano debiera ser partícipe de cuotas concretas de poder. En tales circunstancias, cada ciudadano podría decir, con estricto rigor de verdad: 'el Estado soy yo'."(PÉREZ LUÑO, A.E. Ciudadanía y definiciones. Doxa... p. 189)

${ }^{19} \mathrm{E}$ o autor ainda acrescenta que no caso dos países do terceiro mundo, o sarcasmo representado por estas críticas é ainda maior, eis que tais países assistem à quebra de um Estado Social cujos benefícios não chegaram a desfrutar. (PÉREZ LUÑO, A.E. Ciudadanía y definiciones. Doxa... p. 191)

20 BENHABIB, Seyla. Another Cosmopolitanism..., p. 50-7 
CADEMARTORI, Daniela Mesquita Leutchuk; MORAES, Gabriel Augusto Marques Poeta de. A construção da cidadania, a democracia e a teoria cosmopolita: análise de um caso a partir do fenômeno das iterações democráticas. Revista Eletrônica Direito e Política, Programa de PósGraduação Stricto Sensu em Ciência Jurídica da UNIVALI, Itajaí, v.10, n.2, 10 quadrimestre de 2015. Disponível em: www.univali.br/direitoepolitica - ISSN 1980-7791.

Da teorização que representou o "ápice" da compreensão clássica sobre a cidadania até a de T.H. Marshall no século passado, o conceito transformou-se, tendo se dissociado das premissas de identidade coletiva e privilégios políticos enquanto membro de uma sociedade. Para ilustrar este desenvolvimento na atualidade, a autora formula o conceito de "Iterações Democráticas" quase como que oferecendo soluções normativas e institucionais para o paradoxo da legitimidade democrática. Sucintamente, "Iterações Democráticas" são caminhos complexos de mediação da vontade e da formação de opinião que podem desaguar na readequação da opinião publica e até mesmo das normas jurídicas. $^{21}$

Na União Europeia, todos os cidadãos europeus são portadores de "privilégios políticos", inclusive àqueles que residem em outro território que não o seu de origem. Este é um caso isolado de "desagregação" da cidadania de forma mais intensa, haja visto que ocorre somente entre países pertencentes ao bloco. Os cidadãos dos chamados EU's Third Country ${ }^{22}$ tem seus direitos políticos ainda vinculados às suas nacionalidades e culturas de origem. Ainda assim percebe-se uma mudança em alguns países da União Europeia. Na Dinamarca, Suécia, Finlândia e Holanda, por exemplo, os EU's Third Country podem participar de eleições regionais. Na Irlanda estes direitos são garantidos a nível local, mas não regional. No Reino Unido os cidadãos da Commonwealth ${ }^{23}$ podem votar nas eleições nacionais.

\footnotetext{
${ }^{21}$ BENHABIB, Seyla. Another Cosmopolitanism..., p. 51-7

22 "The term 'third country' is used in the Treaties, where it means a country that is not a member of the Union. This meaning is derived from 'third country' in the sense of one not party to an agreement between two other countries. Even more generally, the term is used to denote a country other than two specific countries referred to, e.g. in the context of trade relations. This ambiguity is also compounded by the fact that the term is often incorrectly interpreted to mean 'third-world country'." (EUROFOUND. Third-country nationals. Disponível em: www.eurofound.europa.eu. Acesso em: 22 de março de 2014.)

23 "A Comunidade das Nações ( Commonwealth) é composta, atualmente, por 54 Estados. Sua origem remonta ao antigo Império Britânico, que teve fim nos anos 1960. Não foi estabelecida por um tratado, mas por uma série de declarações de princípios exortatórias, das quais as mais significativas foram emitidas em Cingapura, em 1971, e em Harare, em 1991; estas foram combinadas numa nova declaração na Cúpula dos Líderes da Commonwealth de Port-of-Spain em novembro de 2009. Hoje, há um certo consenso no sentido de que seus objetivos políticos e econômicos encontram-se no campo do desenvolvimento e da governança. No entanto, a Commonwealth tem gradualmente ganhado importância na promoção e na proteção dos direitos humanos dos seus dois bilhões de cidadãos [...]."(BOURNE, Richard. Commonwealth of Nations:
} 
CADEMARTORI, Daniela Mesquita Leutchuk; MORAES, Gabriel Augusto Marques Poeta de. A construção da cidadania, a democracia e a teoria cosmopolita: análise de um caso a partir do fenômeno das iterações democráticas. Revista Eletrônica Direito e Política, Programa de PósGraduação Stricto Sensu em Ciência Jurídica da UNIVALI, Itajaí, v.10, n.2, 10 quadrimestre de 2015. Disponível em: www.univali.br/direitoepolitica - ISSN 1980-7791.

Duas conclusões podem ser tiradas desse fenômeno. Primeiro, a de que a garantia dos direitos não mais depende da condição de cidadão - se estrangeiro ou não. E que estrangeiros, legais, podem ser introduzidos nos regimes civis e sociais, assim como protegidos por legislações sub e supranacionais. Mesmo assim a condição dos desprovidos de documentos continua - assim como a dos refugiados e daqueles que procuram por asilo - no "sombrio" domínio jurídico entre a legalidade e ilegalidade. ${ }^{24}$ Estes não têm nenhum tipo de garantia jurídica no que diz respeito ao domicilio e ao emprego.

Afirmar o fim do modelo unitário de cidadania não significa defender a ideia de que a nossa imaginação política ou a força normativa, responsáveis pelas nossas instituições, cresçam de forma obsoleta. Apenas, que passa a ser necessário imaginar formas de políticas que antecipem novas modalidades de cidadania. Neste sentido pode-se tomar o conceito de "Iterações Democráticas" para analisar como a sociedade civil vem participando no desenvolvimento no modelo clássico de cidadania. Analisar-se-á aqui o episódio da L'Affaire du Foulard (The Scarff Affair) ${ }^{25}$, citado na obra da autora Seyla Benhabib. A situação envolve um incidente ocorrido na França no ano de 1989, quando três estudantes de origem islâmica tiveram o seu "direito" de vestir a hijab ${ }^{26}$, negligenciado pelo colégio Gabriel-Havez of Creil. No incidente, ao contrário de uma combinação previamente firmada entre a diretora e os pais das estudantes, estas resolveram usar o véu, aparentemente encorajadas por M. Daniel Yassuf Lecrerq, líder da

estratégias intergovernamentais e não-governamentais para a proteção dos direitos humanos em uma instituição pós-colonial. Sur. Revista Internacional de Direitos Humanos. Sur - Rede Universitária de Direitos Humanos. V. 7, n. 12, p. 37-56, junho de 2010. Disponível em: www.surjournal.org. Acesso em: 22 de março de 2014, p. 37)

${ }^{24}$ Os refugiados e asilados tem garantias médicas e em alguns casos suas crianças podem frequentar a escola. Enquanto os imigrantes ilegais não têm garantias alguma, e quase todos moram e trabalham em condições clandestinas.

25 O Caso do Véu.

26 "A questão do 'hijab' ou véu islâmico é um ponto polemic para os não-muçulmanos (e até para alguns muçulmanos). [...] Este termo frequentemente assume vários significados que vão desde a colocação de um lenço para cobrir os cabelos até um véu, no sentido real da palavra, cobrindo o rosto da muçulmana. Deve-se ressaltar que a maioria dos estudiosos muçulmanos não consideram [sic] obrigatório cobrir o rosto, baseados em interpretações dos versículos do Alcorão e em um 'hadith' do profeta (SAWS) que diz que a muçulmana deve cobrir todo o corpo com exceção do rosto e das mãos (e eventualmente também os pés). De qualquer forma nada impede que a muçulmana cubra o rosto se assim desejar, por acreditar que fica menos sujeita ao assédio ou se considerar que é um dever religioso."(O "hijab" ou "véu islâmico". Disponível em: www.islamicchat.net. Acesso em: 22 de março de 2014.) 
CADEMARTORI, Daniela Mesquita Leutchuk; MORAES, Gabriel Augusto Marques Poeta de. A construção da cidadania, a democracia e a teoria cosmopolita: análise de um caso a partir do fenômeno das iterações democráticas. Revista Eletrônica Direito e Política, Programa de PósGraduação Stricto Sensu em Ciência Jurídica da UNIVALI, Itajaí, v.10, n.2, $1^{0}$ quadrimestre de 2015. Disponível em: www.univali.br/direitoepolitica - ISSN 1980-7791.

organização Ïntegrité e ex-presidente da National Federation of Muslims in France (Federação Nacional dos Muçulmanos). Para Benhabib, o fato das estudantes estarem em contato com M. Lecrerq, indica que o desrespeito a uma combinação previamente firmada, tem sim, um caráter político, consubstanciando a atitude das alunas como um ato que denota identidade, desafio e mesmo exibição de características religiosas muçulmanas e norteafricanas em um cenário em que fora solicitado que estas manifestações não fossem realizadas, de acordo com uma realidade igualitária, secularista (laïcité) ${ }^{27}$ e de respeito ao ideal republicano, considerando serem elas estudantes da nação francesa. Este contencioso acabou por gerar um amplo debate, em que ficou evidenciada a dificuldade de manutenção da tradição francesa da laïcité frente a uma crescente pressão multicultural gerada pela presença de EU's thirdgenetarion imigrants ${ }^{28}$ em solo francês. O próprio veredicto do Conseil $d^{\prime} E$ tat sobre o caso foi ambíguo. ${ }^{29}$

Na medida em que - respondendo à demanda encaminhada por Lionel Jospin, Ministro da Educação à época -, o Conseil d'Etat mencionou a adesão dos textos legais e constitucionais franceses ao conteúdo do discutido em muitas conferências internacionais e invocou a necessidade de fazer justiça ao principio de laïcité conciliando-a com a liberdade de consciência das estudantes, acabou por demonstrar o caráter embrionário da discussão sobre o tema junto à sociedade francesa. Na ocasião as autoridades do colégio foram as encarregadas de interpretar e decidir sobre o contencioso.

Para Benhabib, o tema deveria ter sido melhor desenvolvido por parte das alunas e das pessoas que as encorajaram a usar o véu. O processo de aprendizagem,

\footnotetext{
${ }^{27}$ A laicidade consiste em "[...] um arranjo político no qual a liberdade de consciência se encontra em conformidade com uma vontade de igual justiça para todos, garantida por um Estado neutro em relação a diferentes concepções da vida ideal que coexistem na sociedade."(BAUBÉROT, J.; MILOT, M. Laïcités sans fronteires. Apud GIUBELLI, E. Fronteiras da laicidade. Revista Brasileira das Ciências Sociais. Anpocs, São Paulo, V. 27, n. 79, junho de 2012. Disponível em: www.scielo.br/scielo.php?pid=S0102-69092012000200014\&script=sci_arttext. Acesso em: 22 de março de 2014.)

${ }^{28}$ Imigrantes europeus de terceira geração.

${ }^{29}$ Ver Anexo 1.
} 
CADEMARTORI, Daniela Mesquita Leutchuk; MORAES, Gabriel Augusto Marques Poeta de. A construção da cidadania, a democracia e a teoria cosmopolita: análise de um caso a partir do fenômeno das iterações democráticas. Revista Eletrônica Direito e Política, Programa de PósGraduação Stricto Sensu em Ciência Jurídica da UNIVALI, Itajaí, v.10, n.2, 10 quadrimestre de 2015. Disponível em: www.univali.br/direitoepolitica - ISSN 1980-7791.

ou neste caso, de amadurecimento da sociedade frente as novas realidades, precisa ser levado a cabo com a assumpção de uma nova postura.

[...] as próprias garotas, e os seus incentivadores, na comunidade Islâmica e em qualquer outro lugar, devem aprender a dar uma justificação dos seus atos utilizando-se de boas razões, na esfera publica. Buscando respeito e tratamento igualitário pelas suas crenças religiosas, eles precisam esclarecer como eles pretendem lidar com as diferenças de outras crenças, e como, efetivamente, eles institucionalizariam a separação da questão religiosa dentro da tradição islâmica. ${ }^{30}$

No episódio pode-se perceber um processo em que transparece o que Benhabib denomina de Iterações Democráticas. O evento determinou que movimentos civis começassem a buscar uma maior liberdade de expressão no que diz respeito ao uso de vestimentas de cunho religioso e tais manifestações foram aos poucos ampliando o debate na sociedade civil. Em todas as situações, a cultura deve ser definida de acordo com as características e justificações da sociedade e em democracias liberais deve-se aprender a viver com as diferenças, dentre elas a das vestimentas religiosas. A partir daí, os aspectos culturais "estranhos" à realidade em questão devem ser internalizados por meio do desenvolvimento da norma. ${ }^{31}$

Apesar do uso do véu ter sido banido na recente legislação francesa, o debate sobre o tema remanesce, tanto é assim que em abril de 2003 o New York Times reportou a formação de um Conselho Muçulmano oficial. Dentre outras prerrogativas, este conselho trata dos direitos das mulheres islâmicas no local de trabalho. Karima Debza, uma argelina mãe de três crianças demonstrou, em poucas palavras, o seu desejo por um processo de Iterações Democráticas: "Eu não consigo achar trabalho aqui por causa do meu véu [...] o meu véu é parte de

\footnotetext{
30 " $[\ldots]$ the girls themselves and their supporters, in the Muslim community and elsewhere, have to learn to give a justification of their actions with a good reasons in the public sphere. In claiming respect and equal treatment for their religious beliefs, they have to clarify how they intend to treat the beliefs of other from different religions, and how, in effect, they would institutionalize the separation of religion and the state within Islamic tradition." (tradução livre - BENHABIB, Seyla.
}

Another Cosmopolitanism...,p. 57)

${ }^{31}$ BENHABIB, Seyla. Another Cosmopolitanism..., p. 58 e ss. 
CADEMARTORI, Daniela Mesquita Leutchuk; MORAES, Gabriel Augusto Marques Poeta de. A construção da cidadania, a democracia e a teoria cosmopolita: análise de um caso a partir do fenômeno das iterações democráticas. Revista Eletrônica Direito e Política, Programa de PósGraduação Stricto Sensu em Ciência Jurídica da UNIVALI, Itajaí, v.10, n.2, 10 quadrimestre de 2015. Disponível em: www.univali.br/direitoepolitica - ISSN 1980-7791.

mim. Eu não vou tirar ele. Nós temos de educar o Estado sobre o quão importante é o véu [...] e porque não deveriam ter medo dele." 32

Temos de aprender a viver e a conviver com o que Michael Walzer descreve como sendo o "Liberalismo e a Arte da Separação":

Eu sugiro pensarmos o liberalismo como uma forma de desenhar o mapa social e político do mundo. O mapa antigo, pré-liberal, mostrava uma grande massa de terra indiferenciada, com rios e montanhas, cidades e vilas, mas sem fronteiras [...] Isto pode ser visto acima de aspectos religiosos, ou políticos, ou econômicos, ou familiares, mas todos estes juntos e formando uma unidade singular [...] Confrontando esse mundo, os teoristas liberais proclamaram e praticaram a arte da separação. Eles desenham linhas, com diferentes regiões, e criaram o mapa sociopolítico no qual estamos familiarizados. ${ }^{33}$

As características culturais estão profundamente entrelaçadas às interpretações das necessidades dos indivíduos e grupos, suas visões de vida e seus sonhos para o futuro. Considerando que essas características se transformam rapidamente, o processo de internalização de uma cultura estranha torna-se imprescindível para o desenvolvimento da sociedade.

\section{CONCLUSÕES PROVISÓRIAS}

A problemática de inserção do estrangeiro na sociedade é uma questão de suma importância quando se analisa o processo de globalização e as suas consequências. Conforme visto, ainda que isto tenha consequências positivas,

\footnotetext{
32 "I cannot find work here because of my head scarf [...] my head scarf is part of me. I won't take it off. We have to educate the state about why the scarf is so important [...] and why there should be no fear of it" (tradução livre - BENHABIB, Seyla. Another Cosmopolitanism..., p. 58)

33 "I suggest that we think of liberalism as a certain way of drawing the map of the social and political world. The old, preliberal map showed a largely undifferentiated land mass, with rivers and mountains, cities and towns, but no borders [...] It might be viewed under the aspect of religion, or politics, or economy, or family, but all these interpenetrated one another and constituted a single reality [...] Confronting this world, liberal theorists preached and practiced and art of separation. They drew lines, marked off different realms, and created the sociopolitical map with which we are still familiar." (tradução livre - WALZER, Michael. Liberalism and the Art of Separation. Political Theory, Sage Publications, Inc., v.12, n. 3, p . 315-330, aug.1984. Disponível em: http://www.sss.ias.edu/files/pdfs/Walzer/LiberalismArtofSeparation.pdf. Acesso em: 22 de março de 2014, p. 315)
} 
CADEMARTORI, Daniela Mesquita Leutchuk; MORAES, Gabriel Augusto Marques Poeta de. A construção da cidadania, a democracia e a teoria cosmopolita: análise de um caso a partir do fenômeno das iterações democráticas. Revista Eletrônica Direito e Política, Programa de PósGraduação Stricto Sensu em Ciência Jurídica da UNIVALI, Itajaí, v.10, n.2, $1^{\circ}$ quadrimestre de 2015. Disponível em: www.univali.br/direitoepolitica - ISSN 1980-7791.

como por exemplo as decorrentes do desenvolvimento tecnológico principalmente no que diz respeito à troca de informações - e a as que envolvem a liberdade comercial, não se percebe o mesmo no que diz respeito ao tema dos direitos humanos. Essa talvez seja a maior incongruência do fenômeno da globalização. O indivíduo, principal incentivador de tal processo, ainda não tem seus direitos garantidos quando ultrapassa as fronteiras de seu território de origem. ${ }^{34}$ Nesse sentido o estudo da Teoria Cosmopolita possibilita um campo de visualização maior na medida em que analisa o movimento migratório, por exemplo, sob a perspectiva do individuo e não mais somente do Estado que o acolhe. E mais, analisa como podem ser inseridas normas cosmopolitas em um ambiente liberal democrático embora esse não as reconheça.

Conforme citado, percebe-se as transformações do conceito clássico de cidadania até aquelas estudadas na década de cinquenta do século passado por Thomas $\mathrm{H}$. Marshall. Atualmente, estrangeiros mesmo não compartilhando uma identidade cultural pressuposta, gozam de direitos políticos, ainda que mínimos. Tais prerrogativas ainda não atingem os que não possuem os requisitos mínimos para serem considerados "parte da sociedade", ou seja, os requerentes a asilo e os refugiados. Essa situação faz com que as transformações teóricas devam, inevitavelmente, ser acompanhadas por transformações das normas jurídicas. A forte carga jusnaturalista dos direitos humanos não elude que as prerrogativas referentes às garantias sociais e políticas em território estrangeiro necessitem estar positivadas. É nesse sentido que o processo descrito através das Iterações Democráticas, ao oferecer possibilidades de mediação da vontade na formação da opinião pública, torna-se ímpar quando se tem em mente a readequação dessa opinião, bem como das normas jurídicas subsequentes.

Como demonstrado no exemplo da mãe argelina que não conseguia emprego por conta do seu véu, a transformação da norma jurídica está intimamente relacionada ao debate destas questões. Ainda que no caso francês tenha sido aprovada uma lei que impede o uso de objetos de cunho religioso em público,

34 Com exceção para aqueles cidadãos de Estados que mantem acordos bilaterais específicos ou de blocos. 
CADEMARTORI, Daniela Mesquita Leutchuk; MORAES, Gabriel Augusto Marques Poeta de. A construção da cidadania, a democracia e a teoria cosmopolita: análise de um caso a partir do fenômeno das iterações democráticas. Revista Eletrônica Direito e Política, Programa de PósGraduação Stricto Sensu em Ciência Jurídica da UNIVALI, Itajaí, v.10, n.2, 10 quadrimestre de 2015. Disponível em: www.univali.br/direitoepolitica - ISSN 1980-7791.

canais de interlocução para problemas com essas características foram criados graças ao aquecimento do debate na sociedade civil.

\section{REFERÊNCIAS DAS FONTES CITADAS}

APPIAH, Kwame Anthony. Cosmopolitanism: ethics in a world of strangers. New York: W.W. Norton \& Company, 2006, p. 113

BELLER, Elisa T. The Headscarf Affair: The Conseil d'État on the Role of Religion and Culture in French Society. Texas International Law Journal. Disponível em: http://www.tilj.org/content/journal/39/num4/Beller581.pdf Acesso em: 22 de outubro de 2013

BENHABIB, Seyla. Another Cosmopolitanism. Oxford: Oxford University Press, 2006.

BOBBIO, Norberto. O Futuro da democracia: uma defesa das regras do jogo Tradução de M. A. Nogueira. São Paulo: Paz e Terra, 1986. Título original: Il futuro della democrazia. Una difesa delle regole del gioco.

BOURNE, Richard. Commonwealth of Nations: estratégias intergovernamentais e não-governamentais para a proteção dos direitos humanos em uma instituição pós-colonial. Sur. Revista Internacional de Direitos Humanos. Sur - Rede Universitária de Direitos Humanos. V. 7, n. 12, p. 37-56, junho de 2010. Disponível em: www.surjournal.org. Acesso em: 22 de março de 2014

EUROFOUND. Third-country nationals. Disponível em: <www.eurofound.europa.eu>. Acesso em: 22 de março de 2014.

GIDDENS, Anthony. Sociologia. Tradução de Sandra Regina Netz. 4.ed. Porto Alegre: 2005.

GIUBELLI, E. Fronteiras da laicidade. Revista Brasileira das Ciências Sociais. Anpocs, São Paulo, V. 27, n. 79, junho de 2012. Disponível em: www.scielo.br/scielo.php?pid=S0102-69092012000200014\&script=sci_arttext. Acesso em: 22 de março de 2014.

HARDT, Michael; NEGRI, Antonio. Império. Tradução de Berilo Vargas. 6.ed. Rio de Janeiro: Record, 2004.501p.

KANT, Immanuel. A Paz Perpétua: um projeto filosófico. Tradução de Artur Mourão. Covilhã: Universidade da Beira Interior, 2008. Disponível em: www.lusofonia.net. Acesso em: 22 de março de 2014

MARSHALL, Thomas Humphrey. Cidadania, classe social e status. Tradução de Meton Porto Gadelha. Rio de Janeiro: Zahar, 1967. 220p. Título original: Sociology at the Crossroads and other essays

PÉREZ LUÑO, A.E. Ciudadanía y definiciones. Doxa. Cuadernos de Filosofia del Derecho, Alicante, n. 25, p. 177-210, 2002. Disponível em: Acesso em: 22 de março de 2014. 
CADEMARTORI, Daniela Mesquita Leutchuk; MORAES, Gabriel Augusto Marques Poeta de. A construção da cidadania, a democracia e a teoria cosmopolita: análise de um caso a partir do fenômeno das iterações democráticas. Revista Eletrônica Direito e Política, Programa de PósGraduação Stricto Sensu em Ciência Jurídica da UNIVALI, Itajaí, v.10, n.2, 10 quadrimestre de 2015. Disponível em: www.univali.br/direitoepolitica - ISSN 1980-7791.

Derechos Humanos, Estado de Derecho y Constitucion. 5.ed.

Madrid: Tecnos, 1995.

RUBIO CARRACEDO, José. Introducción. In: ; ROSALES, José Maria;

TOSCANO MÉNDEZ, Manuel. Ciudadanía, nacionalismo y derechos

humanos. Madrid: Trotta, 2000. 231p.

SARLET, Ingo Wolfgang. A eficácia dos direitos fundamentais. 3.ed. rev., atual. e amp. Porto Alegre: Livraria do Advogado, 2003. 416p.

UNITED NATIONS. General Assembly. International Migration and Development Report of the Secretary-General. Disponível em

http://www.un.org/esa/population/migration/ga/SG_Report_A_68_190.pdf .

Acesso em: 16 de novembro de 2013.

WALZER, Michael. Liberalism and the Art of Separation. Political Theory, Sage Publications, Inc., v.12, n. 3, p . 315-330, aug.1984. Disponível em:

http://www.sss.ias.edu/files/pdfs/Walzer/LiberalismArtofSeparation.pdf. Acesso em: 22 de março de 2014

\section{ANEXOS}

\section{Anexo 1}

Conclusão do Conseil d'Etat à época:

"[...] the wearing by students, in the schools, of signs whereby they believe to be manifesting their adherence to one religion is itself no incompatible with the principle of laicité, since it constitutes the exercise of theirs liberty of expression and manifestation of their religious beliefs; but this liberty does no permit students do exhibit signs of religious belonging which, by their nature, by the conditions under which they are worn individually of collectively, or by their ostentatious or combative character, would constitute an act of pressure, provocation, proselytizing or propaganda, threatening to the dignity or liberty of the student or to the other member of the educational community, compromising their health or their security, disturbing the continuation of instructional activities or the educational role of the instructors, in short, that would disturb proper order in the establishment or the normal functioning of public service"

FONTE: BENHABIB, Seyla. Another Cosmopolitanism. Oxford: Oxford University Press, 2006, p. 52-53

Submetido em: Abril/2015

Aprovado em: Abril/2015 